\title{
A MetaStable PHASE IN $\alpha$-Ti-Fe REVEALED BY MÖSSBAUER ANALYSIS (*)
}

\author{
M. M. STUPEL, M. RON and B. Z. WEISS
}

Department of Materials Engineering, Technion, Haifa, Israel

\begin{abstract}
Résumé. - On montre que dans le système binaire Ti-Fe, pour des concentrations de fer $C_{\mathrm{Fe}} \leqslant 0,5 \%$, des transitions de phase peuvent être étudiées avec une grande sensibilité par effet Mössbauer.

On a trouvé que les déplacements isomériques de $\alpha$ et $\alpha_{\mathrm{m}}-\mathrm{Ti}-\mathrm{Fe}$ sont $0,00 \pm 0,01 \mathrm{~mm} / \mathrm{s}$ et $0,025 \pm 0,01 \mathrm{~mm} / \mathrm{s}$ respectivement par rapport au fer $\alpha$.

Une raie située à - $-0,275 \mathrm{~mm} / \mathrm{s}$ par rapport au fer $\alpha$ a été mise en évidence et attribuée à une phase métastable par rapport à TiFe, appelée phase $\theta$. On montre qualitativement l'influence sur cette réaction de la température de vieillissement, de la durée du vieillissement et de la concentration en fer.

Abstract. - It is shown that in the binary system Ti-Fe, at concentrations of $C_{\mathrm{Fe}} \leqslant 0.5 \%$, phase transitions can be studied with high sensitivity by the Mössbauer effect.

The isomer shift of $\alpha$ and $\alpha_{\mathrm{m}}$-Ti-Fe were found to be : $0.00 \pm 0.01 \mathrm{~mm} / \mathrm{s}$ and $0.025 \pm 0.01 \mathrm{~mm} / \mathrm{s}$ respectively, relative to $\alpha$-iron.

A line positioned at $-0.275 \mathrm{~mm} / \mathrm{s}$, relative to $\alpha$-iron, has been differentiated and related to a phase, designated- $\theta$, metastable relative to TiFe. The dependence of the reaction on aging temperature, aging time and the content of iron is qualitatively shown.
\end{abstract}

1. Introduction. - The solubility of iron in $\alpha$-Ti-Fe is still subject to controversy. A solubility of less than $0.5 \mathrm{w} / \mathrm{o}$ of $\mathrm{Fe}$ in $\alpha$-Ti has been established $[1,2]$. Raub et al. [3] has found by a metallographic investigation a much lower solubility, namely : $0.05 \mathrm{a} / \mathrm{o} \mathrm{Fe}$ at $700^{\circ} \mathrm{C}$ and less than $0.01 \mathrm{a} / \mathrm{o} \mathrm{Fe}$ at $500^{\circ} \mathrm{C}$. Titanium rich, Ti-Fe alloys are known to undergo martensitic transformation when they are rapidly cooled from the $\beta$-region [4]. Several types of martensite have been reported in Ti-alloys, but in $\alpha$-Ti-Fe only the hexagonal martensite is expected to appear $[4,5]$. This hexagonal martensite which is usually designated by $\alpha^{\prime}$ is given in this study as $\alpha_{\mathrm{m}}$.

The precipitation of $\beta$-phase during aging of Ti-Fe martensite has been mentioned by Wiliams [5] referring to unpublished results (ref. 79 in [5]). The formation of metastable species in the process of aging of $\alpha$-Ti-Fe martensite has so far not been reported.

With respect to the decomposition of $\alpha$-martensite it has been pointed out [5] that X-ray diffraction is not capable of following changes in composition of the $\alpha$-phase because the insensitivity of the h. c. p. lattice parameter to minor variations in composition.

In the present study, using the Mössbauer effect, it was possible to detect an isothermally produced phase,

$\left({ }^{*}\right)$ This research was supported by the National Council for Research and Development of Israel and ELSCINT Limited, Haifa. metastable relative to the stable precipitate TiFe. The Mössbauer characteristics of the phases detected in the process of aging, are given here and also the dependence of the reaction on temperature, time and concentration is qualitatively shown.

2. Experimental procedure. - The alloys for this study were prepared by melting titanium and iron enriched in $\mathrm{Fe}^{57}$ in an arc furnace with a non consumable electrode. The argon gas was dried and carefully cleaned of hydrogen and oxygen. The buttons obtained from the arc melting were cut and cold worked into foils of $30-60 \mu \mathrm{m}$ thickness. These specimens were sealed under high vacuum, in quartz ampules and treated at $1000^{\circ} \mathrm{C}$ for at least 5 hours for the purpose of homogenization. Specimens were quenched from $1000{ }^{\circ} \mathrm{C}$ by dropping the ampules into ice brine and immediately breaking them. Isothermal aging was carried out in a continuously evaluated heated quartz tube. The iron content of the alloys was found by chemical analysis to be : 0.08 w/o-Fe, 0.22 w/o-Fe and $0.40 \mathrm{w} / \mathrm{o}-\mathrm{Fe}$. The amount of interstitial impurities has been tested at various stages and was estimated to be : $H<0.02 \mathrm{w} / \mathrm{o}, 0<0.06 \mathrm{w} / \mathrm{o}, N<0.02 \mathrm{w} / \mathrm{o}$.

The spectra were taken with the aid of an Elscint type Mössbauer spectrometer [6] and a $25 \mathrm{mCi}$ single line source of $\mathrm{Co}^{57}$ in $\mathrm{Pd}$ matrix. The spectrometer was calibrated relative to the 2 -inner lines of $\alpha-\mathrm{Fe}$ and a Sodium Nitroprusside absorber ; the line width 
of the inner lines of the $\alpha-\mathrm{Fe}$ was $0.23 \mathrm{~mm} / \mathrm{s}$. The spectra were analyzed as a superposition of two (or three) single Lorentzian shaped lines. The experimental data was analyzed by least squares best fit performed by means of a $370 / 165$ I. B. M. Computer.

3. Results and interpretation. - In the binary system $\mathrm{Ti}-\mathrm{Fe}$, at concentrations of $C_{\mathrm{Fe}} \leqslant 0.5 \mathrm{w} / \mathrm{o}$ and temperatures below $600^{\circ} \mathrm{C}, \alpha$ and $\mathrm{TiFe}$ are the two stable phases [2]. A simple calculation shows that, for $C_{\mathrm{Fe}} \leqslant 0.4 \mathrm{w} / \mathrm{o}$, the ultimate amount of TiFe cannot exceed $0.5 \mathrm{w} / \mathrm{o}$. Such amounts are practically undetectable by X-ray diffraction methods.

On the other hand, when samples alloyed with iron enriched to $90 \% \mathrm{Fe}^{57}$ are used the Mössbauer effect is highly sensitive in detecting and identifying phases. For thin absorbers the relative integral intensity for a particular ( $i$-th) phase is proportional to the number of iron atoms in that phase which is in turn proportional to the product ; $X_{i} C_{i}$; where $X_{i}$ is the fraction of the $i$-th phase, and $C_{i}$ the concentration of iron in it.

A graphical evaluation shows that at equilibrium [2] and concentrations of $0.05 \leqslant C_{\mathrm{Fe}} \leqslant 0.5 \mathrm{w} / \mathrm{o}$ (as used in this study) the ratio $X_{\alpha} C_{\alpha} / X_{\mathrm{TiFe}} C_{\mathrm{TiFe}}$ changes from $\sim 0.1$ to 5.0. Consequently both $\alpha$ and TiFe are detectable by the Mössbauer effect, although the lines are not always fully resolved.

A series of spectra, shown in figure 1 , were taken at room temperature for an alloy Ti-0.4 w/o Fe. The alloy was quenched from a solution treatment temperature of $1000^{\circ} \mathrm{C}$, then aged at $310^{\circ} \mathrm{C}$ for various periods. The intensity of a satellite peak, located at $-0.275 \pm 0.01 \mathrm{~mm} / \mathrm{s}$ is seen to increase with the aging time. This line was designated $\theta$ and related to a transition phase, metastable relative to the ultimate equilibrium TiFe. No TiFe was observed for aging at $360^{\circ} \mathrm{C}$ for periods of more than 100 hours. The Mössbauer parameters for the phases under consideration are given in Table $\mathrm{I}$.

A short aging period. was sufficient to shift the position of the right hand peak from $0.00 \pm 0.01 \mathrm{~mm} / \mathrm{s}$ to $0.025 \pm 0.01 \mathrm{~mm} / \mathrm{s}$. No further change in the position of this line was observed for longer aging

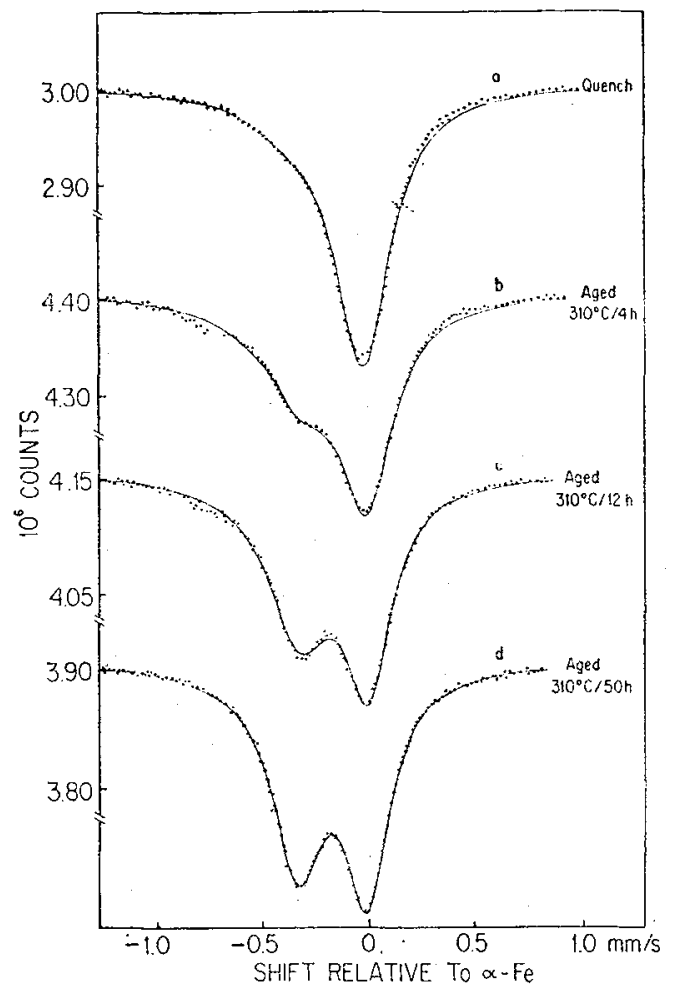

FIG. 1. - Room temperature Mössbauer spectra for an alloy $\mathrm{Ti}-0.4 \mathrm{w} / \mathrm{O} \mathrm{Fe}$, quenched from $1000^{\circ} \mathrm{C}$ and aged at $310^{\circ} \mathrm{C}$ : a) as quenched, $b$ ) aged for 4 hours, c) aged for 12 hours and d) aged for 50 hours.

periods. This line was identified as representing $\alpha$-martensite $\left(\alpha_{m}\right)$ in the as-quenched condition and equilibrium $\alpha-\mathrm{Ti}(\mathrm{Fe})$ after aging. Debye-Scherer $\mathrm{X}$-ray diffraction patterns show no phase other than the h. c. p. $\alpha$-phase in all samples for all treatments mentioned here. The position of the $\alpha$-line found here is in slight disagreement with that reported by Rupp [7], but differs appreciably from that reported by Bokshteyn et al. [8]. The $\alpha$ and $\alpha_{\mathrm{m}}$ lines have previously not been resolved from each other [7].

In order to study the concentration dependence of the rate of growth of the metastable $\theta$-phase, alloys

TABLE I

Room temperature Mössbauer parameters of $\alpha, \alpha_{\mathrm{m}}$ and $\theta$-phases for a Ti-0.4 w/o Fe alloy

\begin{tabular}{|c|c|c|c|c|c|}
\hline & (I. S.) $\alpha_{\mathrm{m}}\left(^{*}\right)$ & (I. S.) $\alpha(*)$ & (I. S.) $\theta\left({ }^{*}\right)$ & $I \theta / I \alpha$ & Reference \\
\hline Quench & 0.000 & & & & this work \\
\hline Aged $310^{\circ} \mathrm{C} / 4 \mathrm{~h}$ & & 0.022 & -0.265 & 0.50 & - \\
\hline Aged $310^{\circ} \mathrm{C} / 12 \mathrm{~h}$ & & 0.026 & -0.278 & 0.78 & - \\
\hline Aged $310^{\circ} \mathrm{C} / 24 \mathrm{~h}$ & & 0.024 & -0.285 & 0.87 & - \\
\hline Aged $310^{\circ} \mathrm{C} / 50 \mathrm{~h}$ & & 0.020 & -0.265 & 0.90 & - \\
\hline & & 0.055 & & & Rupp [7] \\
\hline & & 0.330 & & & $\begin{array}{l}\text { Bokshteyn } \\
\text { et al }[8]\end{array}$ \\
\hline
\end{tabular}

(*) In $\mathrm{mm} / \mathrm{s}$ relative to $\alpha$-iron; accuracy better than \pm 0.01 . 
of various iron concentrations were prepared, quenched and aged isothermally at the same temperature and for the same period of time.

Mössbauer spectra, shown in figure 2, were taken at room temperature for three alloys, containing 0.08 , 0.22 and $0.40 \mathrm{w} / \mathrm{o} \mathrm{Fe}$, all of which were quenched from $1000^{\circ} \mathrm{C}$ and aged at $320^{\circ} \mathrm{C}$ for 10 hours.

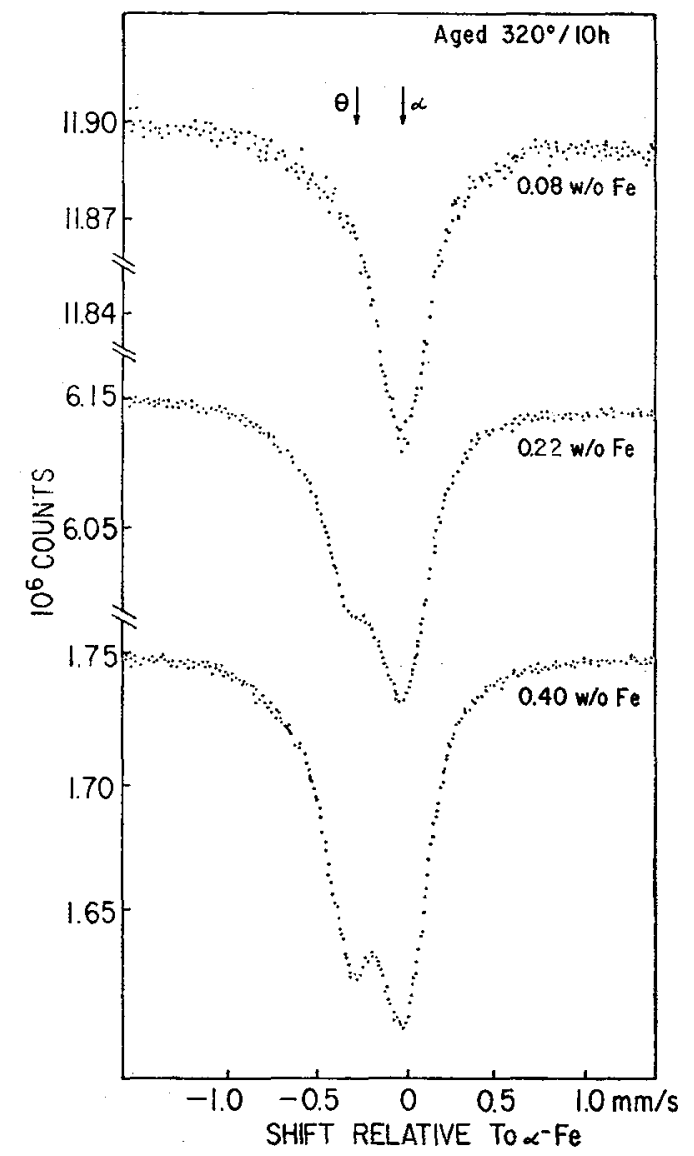

FIG. 2. - Room temperature Mössbauer spectra of alloys, aged at $320^{\circ} \mathrm{C}$ for 10 hours, of following compositions : $0.08 \mathrm{w} / \mathrm{o} \mathrm{Fe}$, 0.22 w/o Fe, 0.4 w/o Fe.

The Mössbauer characteristics of these spectra are summarized in Table II. It is clearly seen, from the

\section{TABLE II}

Room temperature Mössbauer parameters of $\alpha$ and $\theta$-phases for Ti-0.08 w/o Fe, Ti-0.22 w/o Fe and Ti-0.40 w/o Fe alloys, aged at $320^{\circ} \mathrm{C}$ for 10 hours.

$\begin{array}{cccc}\text { Fe w/o } & \text { (I. S.) } \alpha\left(^{*}\right) & (\text { I. S. }) \theta(*) & I \theta / I \alpha \\ \overline{0.08} & - & - & - \\ 0.22 & \overline{0.020} & -0.283 & \sim 0 \\ 0.40 & 0.030 & -0.270 & 0.82\end{array}$

(*) In $\mathrm{mm} / \mathrm{s}$ relative to $\alpha$-iron; accuracy better than \pm 0.01 .

spectra, that the relative area related to the $\theta$-phase increases with the concentration of iron in the alloys.

4. Discussion. - The Mössbauer parameters of TiFe, $\alpha$ and $\beta$-Ti-Fe have been published $[7,8]$. The isomer shift, found in the present study, for the $\alpha-\mathrm{Ti}-\mathrm{Fe}$ is in substantial disagreement with that given by Bokshteyn et al. [8]. It also differs slightly from the isomer shift found by Rupp [7], probably due to the fact that the lines of $\alpha$ and $\alpha_{m}$ have not been resolved one from the other.

The isomer shift of $\beta$-Ti-Fe and TiFe were measured carefully and found to agree generally with the values given by Rupp [7]. Also the position of the $\omega$-phase was established and the line related to the $\theta$-phase was differentiated from the other lines.

With the resolution achieved in these experiments, it is possible to follow the decomposition of the supersaturated $\alpha$-solid solution by means of room temperature Mössbauer measurements. The dependence of the reaction on aging temperature, aging time and the iron concentration of the alloy is qualitatively seen from the spectra of figures 1 and 2 .

Work to further reveal the nature and the structure of the species to which the $\theta$-phase is related is currently being undertaken by an electron microscope study.

The aging behaviour of the alloy is also under study using electrical resistivity and mechanical properties measurements.

\section{References}

[1] MCQuillan, A. D., J. Inst. Metals 79 (1951) 73 ;

Van Thyne, R. J., Kessler, H. D., Hansen, M., Trans. Am. Soc. Metals 44 (1952) 974.

[2] Hansen, M., Anderko, K., Constitution of Binary Alloys (McGraw-Hill, N. Y.), 1958, 723.

[3] Raub, E., Raub, Ch. J., Röschel, E., Compton, V. B., Geballe, T. H., Mathias, B. T., J. Less Common Metals 12 (1967) 3b.

[4] Nishiyama, Z., Sato, S., OKa, M., Nakagawa, H., J. Japan
Inst. Metals 30 (1966) 16; J. Japan Inst. Metals 31 (1967) 525 .

[5] Wiliams, J. C., in Titanium Science and Technology. Editors R. I. Jaffee, H. M. Burte. (Plenum Press) V 3, 1973, 1433.

[6] Biran, A., Shoshani, A., Montano, P. A., Nucl. Instrum. Meth. 89 (1970) 21.

[7] Rupp, G., Z. Phys. 230 (1970) 265.

[8] Bokshteyn, B. S., Voytkovskiy, Yu. B., Fiz. Metal. Metalloved. 4 (1970) 893 . 